Article

\title{
Optimum Inhibition of Amphotericin-B-Resistant Candida albicans Strain in Single- and Mixed-Species Biofilms by Candida and Non-Candida Terpenoids
}

\author{
Hidaya F. Z. Touil ${ }^{1}$, Kebir Boucherit ${ }^{1,2}$, Zahia Boucherit-Otmani ${ }^{1}\left(\right.$, Ghalia Kohder ${ }^{3,4}{ }^{\oplus}$, \\ Mohamed Madkour ${ }^{3,5}$ (iD) and Sameh S. M. Soliman ${ }^{3,4,6, *(D)}$ \\ 1 Laboratory Antibiotics Antifungals: Physico-Chemical, Synthesis and Biological Activity (LapSab), \\ Tlemcen University, Tlemcen B.P 119, Algeria; hidayet.touil@gmail.com (H.F.Z.T.); \\ boucheritkebir@yahoo.fr (K.B.); z_boucherit@yahoo.fr (Z.B.-O.) \\ 2 University Center Belhadj Bouchaïb, Aïn Temouchent BP 284, Algeria \\ 3 Sharjah Institute for Medical Research, University of Sharjah, Sharjah PO. Box 27272, UAE; \\ gkhoder@sharjah.ac.ae (G.K.); mmadkour@sharjah.ac.ae (M.M.) \\ 4 Department of Medicinal Chemistry, College of Pharmacy, University of Sharjah, \\ Sharjah PO. Box 27272, UAE \\ 5 Department of Medical Laboratory Sciences, Collage of Health Sciences, University of Sharjah, \\ Sharjah PO. Box 27272, UAE \\ 6 Department of Pharmacognosy, College of Pharmacy, University of Zagazig, Zagazig 44519, Egypt \\ * Correspondence: ssoliman@sharjah.ac.ae; Tel.: +971-6505-7472
}

Received: 28 January 2020; Accepted: 18 February 2020; Published: 21 February 2020

\begin{abstract}
Candida albicans is one of the most common human fungal pathogens and represents the most important cause of opportunistic mycoses worldwide. Surgical devices including catheters are easily contaminated with C. albicans via its formation of drug-resistant biofilms. In this study, amphotericin-B-resistant $C$. albicans strains were isolated from surgical devices at an intensive care center. The objective of this study was to develop optimized effective inhibitory treatment of resistant C. albicans by terpenoids, known to be produced naturally as protective signals. Endogenously produced farnesol by $C$. albicans yeast and plant terpenoids, carvacrol, and cuminaldehyde were tested separately or in combination on amphotericin-B-resistant C. albicans in either single- or mixed-infections. The results showed that farnesol did not inhibit hyphae formation when associated with bacteria. Carvacrol and cuminaldehyde showed variable inhibitory effects on C. albicans yeast compared to hyphae formation. A combination of farnesol with carvacrol showed synergistic inhibitory activities not only on C. albicans yeast and hyphae, but also on biofilms formed from singleand mixed-species and at reduced doses. The combined terpenoids also showed biofilm-penetration capability. The aforementioned terpenoid combination will not only be useful in the treatment of different resistant Candida forms, but also in the safe prevention of biofilm formation.
\end{abstract}

Keywords: highly resistant Candida albicans; mixed infection; biofilm; terpenoids; farnesol; carvacrol

\section{Introduction}

Candida albicans is the fourth most common cause of nosocomial bloodstream infection [1,2]. C. albicans infections are common among hospital patients and elderly people, and are difficult to control [3]. About $50 \%$ of adult people have C. albicans yeasts in their mouths, and it is responsible for superficial, easily treated infections. However, C. albicans infections can spread throughout the body and become life-threatening, particularly with immune-compromised patients [4]. Candidiasis represents a major cause of morbidity and mortality in a broad range of immune-compromised 
patients [5]. C. albicans infections are very difficult to treat due to their resistance to antifungal drugs, expression of virulence factors, and ability to form biofilms. C. albicans can switch between two forms, the yeast and hyphae forms. The switch from yeast to hyphae is a recognized virulence factor of C. albicans [6], since it is mainly associated with drug-resistant biofilm formation. Most candidiases are associated with the formation of biofilms at a wide range of implanted medical devices [7].

Biofilm-related infections caused by $C$. albicans represent a major threat to public health, as these infections are inherently resistant to most antifungal treatments and thus constitute a reservoir for continued infection [8]. Biofilms are usually found on medical devices such as prostheses, cardioverter defibrillators, urinary and vascular catheters, and cardiac devices [9].

C. albicans biofilm exists as complex, diverse, and heterogeneous structures [10] that may be complicated by bacterial infections. These poly-microbial structures (C. albicans/bacteria) can ultimately influence disease severity by promoting intensified pathogenic phenotypes [11], including an increased in resistance to both host defenses and antimicrobial therapies. There are increasingly few antimicrobials available to treat such life-threatening infections [12]. Thus, screening for new antimicrobials is necessary.

Medicinal plants, in particular our daily used plants and condiments, are known sources of antimicrobial terpenoids. Terpenoids are signaling metabolites produced naturally for the purpose of protection. Several terpenoids have been proven to have significant antimicrobial properties [13,14]. Several terpenoids have been shown to exhibit antimicrobial activities by inhibiting morphogenesis, adhesion, and biofilm formation of C. albicans [15], biofilm formation and elastase production by Pseudomonas aeruginosa and Staphylococcus aureus [16], and production of native quorum-sensing compounds [17]. Studies of different terpenoids have revealed that several terpenoid candidates show significant antifungal activity [15], including inhibition of the yeast-to-hyphal transition and biofilm formation in C. albicans. The aim of this study was to develop an optimal inhibition strategy for amphotericin-B-resistant $C$. albicans strains using natural volatile terpenoids. In this study, we tested the anti-Candida inhibitory effects of three terpenoidal compounds including farnesol, carvacrol, and cuminaldehyde (Figure 1). Farnesol is produced endogenously by C. albicans yeast and exogenously in plant foods such as corn cobs. Carvacrol and cuminaldehyde are produced in plant foods and condiments such as oregano and cumin, respectively.

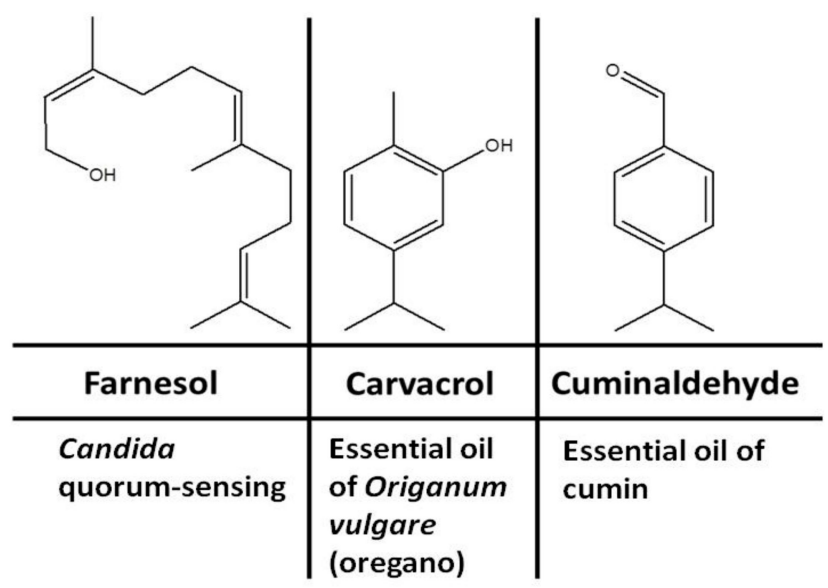

Figure 1. Structures and possible sources of terpenoidal compounds.

\section{Materials and Methods}

\subsection{Bacteria and Candida Strains}

Fifteen clinical C. albicans and 15 clinical bacterial isolates, as listed in Table 1, isolated from medical devices at intensive care department of Tlemcen University Hospital and identified according to Touil et al. (2018), were employed [18]. C. albicans strain ATCC10231 was employed as a reference strain. 
Table 1. Candida and bacterial strains employed in the study.

\begin{tabular}{cccc}
\hline \multicolumn{1}{c}{ Candida } & \multicolumn{2}{c}{ Bacteria } \\
\hline Strain & Symbol & Strain & Symbol \\
\hline Candida albicans 1 & A1 & Escherichia coli & Ec2 \\
\hline Candida albicans 2 & A2 & Escherichia coli & Ec4 \\
\hline Candida albicans 3 & A3 & Escherichia coli & Ec13 \\
\hline Candida albicans 4 & A4 & Providencia stuartii & Ps2 \\
\hline Candida albicans 5 & A5 & Providencia stuartii & Ps3 \\
\hline Candida albicans 6 & A6 & Acinetobacter baumannii & Ab7 \\
\hline Candida albicans 7 & A7 & Acinetobacter baumannii & Ab11 \\
\hline Candida albicans 8 & A8 & Proteus mirabilis & Pm16 \\
\hline Candida albicans 9 & A9 & Proteus mirabilis & Pm18 \\
\hline Candida albicans 10 & A10 & Proteus mirabilis & Pm19 \\
\hline Candida albicans 11 & A11 & Proteus mirabilis & Pm21 \\
\hline Candida albicans 12 & A12 & Staphylococcus aureus & Sa6 \\
\hline Candida albicans 13 & A13 & Staphylococcus aureus & Sa11 \\
\hline Candida albicans 14 & A14 & Staphylococcus aureus & Sa24 \\
\hline Candida albicans 15 & A15 & Staphylococcus epidermidis & Se3 \\
\hline Candida albicans & ATCC10231 & & \\
\hline
\end{tabular}

\subsection{Determination of the Minimum Inhibitory Concentration (MIC)}

The antimicrobial susceptibility of $C$. albicans and bacterial isolates to terpenoidal compounds was determined using the broth microdilution method according to the Clinical and Laboratory Standards Institute (CLSI) for yeast [19] and bacteria [20]. Terpenoidal compounds including farnesol, carvacrol, and cuminaldehyde (Figure 1) and antimicrobial agents including amphotericin B, colistin, and vancomycin were purchased from Sigma Company.

C. albicans biofilm was developed according to well-established protocols [21]. Briefly, $200 \mu \mathrm{L}$ RPMI-1640 containing $5 \times 10^{5}$ cells/mL was incubated in polystyrene, round-bottomed, 96 well microtiter plates (Corning Inc., Corning, NY, USA) (Costar $\left.{ }^{\circledR}\right)$. Terpenoids were applied in the concentrations $1,2,3$, and $4 \mathrm{mg} / \mathrm{mL}$ for cuminaldehyde, $0.25,0.5,1,2$ and $3 \mathrm{mg} / \mathrm{mL}$ for carvacrol, and $0.22 \mathrm{mg} / \mathrm{mL}$ to $66.7 \mathrm{mg} / \mathrm{mL}$ for farnesol [22]. The plates were then incubated at $37^{\circ} \mathrm{C}$ for 4,24 , and $48 \mathrm{~h}$ time periods. The microbial growth was measured at $\mathrm{OD}_{570}$ using a microplate reader (BioTekEL $\times 808$, Agilent, Winooski, VT, USA). Clear wells with the lowest terpenoid concentrations and with no visible growth were considered to represent the minimum inhibitory concentration (MIC).

Amphotericin B was employed as a positive control against $C$. albicans. Cultures without terpenoids or antimicrobial agents were employed as negative controls.

\subsection{Determination of the Minimum Fungicidal/Bactericidal Concentrations (MFC/MBC)}

The two wells containing compound concentrations above the MIC were used to determine the minimum fungicidal concentration (MFC) and minimum bactericidal concentration (MBC). A measure of $20 \mu \mathrm{L}$ from each well was spread on Sabouraud dextrose agar and LB agar and incubated at $37^{\circ} \mathrm{C}$ for $24 \mathrm{~h}$. The MFC and MBC were defined as the lowest concentrations that showed no growth [23].

\subsection{Antimicrobial Activity of Terpenoidal Compounds Combinations against C. albicans and Bacteria}

The efficacy of combinations of terpenoidal compounds including cuminaladehyde/carvacrol and farnesol/carvacrol was analyzed in terms of fractional inhibitory concentration indices (FICI) using a 
checkerboard assay. A measure of $50 \mu \mathrm{L}$ of each compound was dispensed into a 96 well microtiter plate. A $100 \mu \mathrm{L}$ yeast and/or bacterial inoculum was added to obtain a final inoculum concentration of $5.0 \times 10^{5} \mathrm{CFU} / \mathrm{mL}$. The plates were incubated at $37^{\circ} \mathrm{C}$ for $24 \mathrm{~h}$, followed by reading at $\mathrm{OD}_{570}$. The concentrations of combined compounds used were selected based on their MIC value $(\sim 1 / 2 \mathrm{MIC}$, 1/4 MIC, 1/8 MIC, and 1/16 MIC). Terpenoid interactions were classified as synergistic, indifferent, or antagonistic on the basis of FICI [24].

\subsection{Inhibition of Single-Species and Mixed-Species Biofilm Formation}

Single- and mixed-species biofilms of $C$. albicans and bacteria were formed in 96 well microtiter plates $\left(\operatorname{Costar}^{\circledR}\right.$, Taufkirchen, Munich, Germany). An aliquot of $100 \mu l$ of yeast cell suspension was added in the case of single-species biofilms, or $50 \mu \mathrm{l}$ of each yeast and bacterial cell suspension for mixed-species biofilms. The inocula were adjusted in RPMI-1640 to a concentration of 1 to $5 \times 10^{6}$ yeast $/ \mathrm{mL}$ and 1 to $5 \times 10^{8}$ bacteria/mL [25]. The plates were incubated for $4 \mathrm{~h}$ at $37^{\circ} \mathrm{C}$. The supernatants were removed and the biofilms formed were washed twice with PBS ( $\mathrm{pH} 7.2)$ to remove non-adherent cells. RPMI medium $(100 \mu \mathrm{L})$ containing the terpenoidal compounds was added over the adhered cells and the plates were further incubated at $37^{\circ} \mathrm{C}$ for $24 \mathrm{~h}$. The influence of terpenoids on mature biofilms was assessed as follows: 24 or $48 \mathrm{~h}$ biofilms were treated with serial concentrations of the terpenoidal compounds ( MIC, $1.5 \mathrm{MIC}$, and $2 \times \mathrm{MIC})$ and the plates were further incubated at $37^{\circ} \mathrm{C}$ for another $24 \mathrm{~h}$. The supernatant including terpenoidal compounds was removed and the fungal viability was analyzed via 3-(4,5-dimethylthiazol-2-yl)-2,5- diphenyl tetrazolium bromide (MTT) assay [14]. The MIC of the terpenoidal compounds that caused $50 \%$ and $80 \%$ inhibition of $C$. albicans biofilm formation was determined by measuring the metabolic activity of biofilm compared to positive and negative controls.

\subsection{MTT Assay}

The metabolic activity of $C$. albicans cells was evaluated using 3-(4, 5-dimethylthiazolyl-2)-2, 5-diphenyltetrazolium bromide (MTT) assay $[26,27]$ as follows: 96 well microtiter plates were seeded with Candida cells. Terpenoids were applied on the seeded cells. Amphotricin B and DMSO were employed as positive and negative controls, respectively. After treatment, the plates were incubated for 24 or $48 \mathrm{~h}$ prior to analysis using MTT cell proliferation assay. A measure of $20 \mu \mathrm{L}$ MTT reagent was added to each well. The plates were incubated for $24 \mathrm{~h}$ and the liquid was then discarded, followed by the addition of $200 \mu \mathrm{L}$ DMSO. The developed purple color was then measured using a Multiskan Go machine spectrophotometer (Thermo Fisher Scientific, Ratastie, Finland) at $570 \mathrm{~nm}$. A higher absorbance and color intensity indicated a higher activity and viability of the cells. Each experiment was repeated six times.

\subsection{Effect of Terpenoidal Compounds on C. albicans Cell Morphology Using Light Microscopy}

In order to assess the compounds' effects on the architecture of single- and mixed-species biofilms formed by $C$. albicans and bacteria, biofilms produced by three representative $C$. albicans strains (ATCC10231, A5, and A6) were visualized under an inverted microscope (Olympus Life Sciences, Amsinckstraße, Hamburg) at $400 \times$ magnification, following $4 \mathrm{~h}, 8 \mathrm{~h}, 16 \mathrm{~h}$, and $24 \mathrm{~h}$ exposure to terpenoidal compounds.

\subsection{Statistical Analysis}

The data were graphed using Graph Pad 5.0 for Windows (GraphPad Software, La Jolla, CA, USA). The statistical significance was analyzed by one-way analysis of variance (ANOVA) using either Bonferroni's multiple comparisons test or Dunn's multiple comparison test. A $p$-value $<0.05$ was considered significant. 


\subsection{Ethics Statement}

The authors confirm that the adherence to the ethical policies of the journal. Ethical approval and appropriate consent form were obtained as per the Tlemcen University Hospital rules.

\section{Results}

\subsection{Amphotricin-B-Resistant C. albicans Clinical Isolates}

Our recent data indicated that the MIC of amphotericin B for the planktonic forms of C. albicans clinical isolates ranges between $0.25-1 \mu \mathrm{g} / \mathrm{mL}$, and the biofilm formed from all tested strains showed resistance to amphotericin B [18]. High concentrations up to 32 and $64 \mu \mathrm{g} / \mathrm{mL}$ of amphotericin B were required to inhibit the single-species biofilms formed by C. albicans A5 and A6 strains [18], compared to $4 \mu \mathrm{g} / \mathrm{mL}$ required to inhibit the biofilm formed by ATCC10231 strain. On the other hand, we found that the mixed-species biofilm was highly resistant, since $>32$ and $64 \mu \mathrm{g} / \mathrm{mL}$ amphotericin B failed to inhibit the biofilms formed by C. albicans A5 and A6 strains when mixed with two co-isolated bacteria; Providencia stuartii 3 and Staphylococcus aureus 6 . The $\mathrm{SMIC}_{50}$ values of amphotericin B for C. albicans A5 and A6 strains in mixed species were 45 and $78 \mu \mathrm{g} / \mathrm{mL}$.

The aim of this study was to develop an optimal inhibition strategy using natural volatile terpenoids for amphotericin-B-resistant C. albicans A5 and A6 strains in either single- or mixed-species biofilms.

\subsection{C. albicans Inhibition by Endogenous Terpenoid (Farnesol) Was Hyphae-Phenotype-Specific}

Pre-adhered C. albicans A5, either alone (Figure 2A) or mixed with two co-isolated bacteria, Providencia stuartii 3 and S. aureus 6 (Figure 2B), were treated with farnesol at $0,0.7$, and $1.4 \mathrm{mg} / \mathrm{mL}$ for $12 \mathrm{~h}$. Farnesol showed selective inhibition of hyphae formed by C. albicans A5 incubated alone (Figure 2C,D), but not when mixed with co-isolated bacteria (Figure 2E,F), suggesting a decreased susceptibility to farnesol in mixed-species biofilms. Although a concentration of $1.4 \mathrm{mg} / \mathrm{mL}$ farnesol could inhibit Candida hyphae formation, 12-50 times that concentration was required to stop C. albicans yeast growth (Supplementary Table S1), suggesting a selective activity against $C$. albicans hyphae formation.
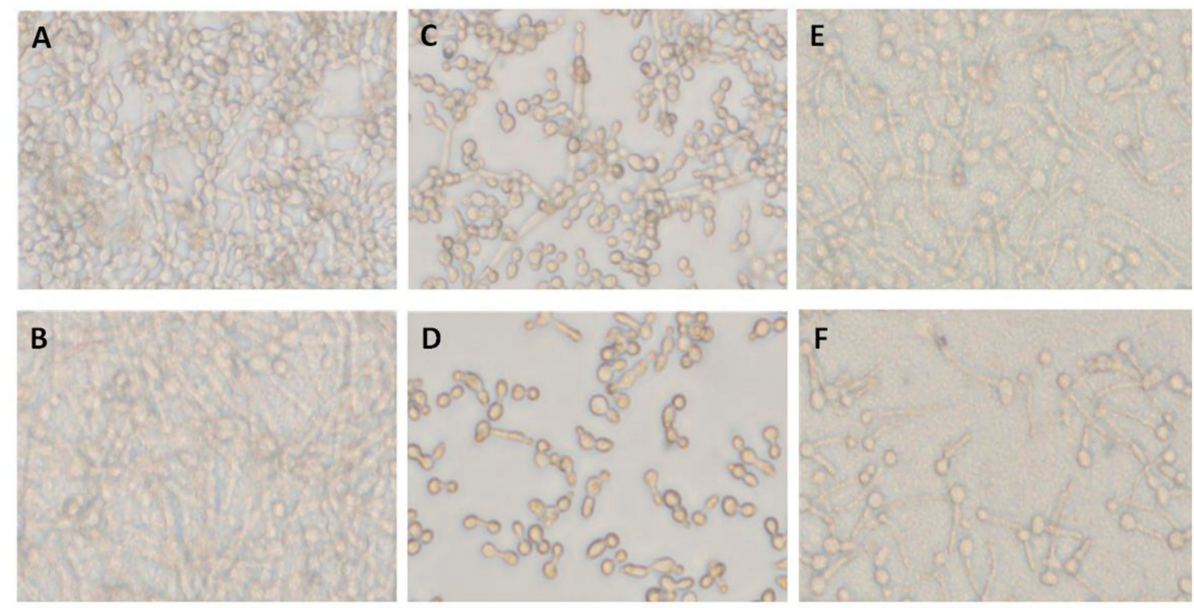

Figure 2. Inhibitory effect of farnesol on single- and mixed-species C. albicans biofilm formation. (A) C. albicans biofilm formed after $12 \mathrm{~h}$ (single-species biofilm A5) (untreated biofilm). (B) Candida biofilm generated by mixed species including C. albicans A5, P. stuartii 3, and S. aureus 6 (A5/Ps3/Sa6). (C) Single-species biofilm formed by A5 treated with farnesol at $0.7 \mathrm{mg} / \mathrm{mL}$. (D) Single-species biofilm formed by A5 treated with farnesol at $1.4 \mathrm{mg} / \mathrm{mL}$. (E) The effect of farnesol at $0.7 \mathrm{mg} / \mathrm{mL}$ on biofilm formed by mixed species including C. albicans A5, P. stuartii 3, and S. aureus 6 (A5/Ps3/Sa6). (F) The effect of farnesol at $1.4 \mathrm{mg} / \mathrm{mL}$ on biofilm mixed-species biofilm formed by C. albicans A5, P. stuartii 3, and S. aureus 6 (A5/Ps3/Sa6). 


\subsection{C. albicans Inhibition by Plant Terpenoids}

The effect of two different plant terpenoids, carvacrol and cuminaldehyde (Figure 1), was tested on C. albicans yeast and the MICs were determined (Supplementary Table S2). The MIC and MFC of carvacrol were determined to be $0.25-1$ and $0.5-2 \mathrm{mg} / \mathrm{mL}$, respectively, and those of cuminaldehyde were $2-4 \mathrm{mg} / \mathrm{mL}$ depending on the Candida isolates (Supplementary Table S2 and Supplementary Figure S1). C. albicans isolates showed higher susceptibility to carvacrol than cuminaldehyde. Carvacrol and cuminaldehyde also showed inhibitory effects on bacteria co-isolated with C. albicans at MIC values of $1 \mathrm{mg} / \mathrm{mL}$ and $1-4 \mathrm{mg} / \mathrm{mL}$, respectively (Supplementary Table S3).

The effect of combining carvacrol and cuminaldeyde was also tested on C. albicans yeast and co-isolated bacteria (Supplementary Table S4). Carvacrol and cuminaldehyde were combined in concentrations lower than their individual MIC values, as indicated in Supplementary Tables S2 and S3. The growth inhibition was determined and FICs were calculated. The FIC index indicates the nature of an interaction between two compounds [24,28].

The checkerboard assay evaluated at $24 \mathrm{~h}$ showed that the combination of carvacrol and cuminaldehyde decreased the $\mathrm{SMIC}_{50}$ values $\sim 8$-fold and 4 -fold compared to the equivalent concentrations of cuminaldehyde and carvacrol when used alone, respectively (Supplementary Table S4). The MIC values of both terpenoids in combination were reduced to $0.06-0.25 \mathrm{mg} / \mathrm{mL} \mathrm{for}$ carvacrol and $0.5-2.0 \mathrm{mg} / \mathrm{mL}$ for cuminaldehyde. The combination showed synergistic interactions (FICI values ranged 0.36 to 0.5 ) for 12 strains of $C$. albicans and indifferent interactions (FICI values between 0.62 and 1.0) for 4 Candida strains (A1, A2, A10, and A12).

\subsection{Inhibition of Single- and Mixed-Species (C. albicans/bacteria) Biofilms by Plant Terpenoids}

In order to evaluate the effect of terpenoids on microbial biofilm formation, biofilms formed by C. albicans (A5, A6, and ATCC10231) were treated with terpenoids as indicated in the Materials and Methods section. The formed biofilms were significantly reduced in the presence of carvacrol (Supplementary Figure S2) ( $p<0.0001$ ) and cuminaldehyde (Supplementary Figure S3), but at higher concentrations than that used in the case of yeast forms (Supplementary Tables S5 and S6). Carvacrol caused an $80 \%$ inhibition in biofilm formation at $2 \mathrm{mg} / \mathrm{mL}$, while cuminaldehyde caused an $80 \%$ inhibition of biofilm formation at $6 \mathrm{mg} / \mathrm{mL}$.

The anti-biofilm activity of terpenoids was also tested on C. albicans mixed with co-isolated bacteria. Mixed-species biofilm formation was significantly inhibited by carvacrol in a concentration-dependent manner, with more than $75 \%$ inhibition at $2 \mathrm{mg} / \mathrm{mL}$ (Figure 3).

On the other hand, cuminaldehyde at $6 \mathrm{mg} / \mathrm{mL}$ caused a $60 \%$ inhibition to biofilm formed by C. albicans A6/S. aureus/Acinetobacter baumannii (Figure 4 ), and at $8 \mathrm{mg} / \mathrm{mL}$ caused $62 \%$ inhibition to biofilm formed by C. albicans A5/P. stuartii/S. aureus (Figure 4).

The results indicated that carvacrol interrupted the interactions among the mixed species and inhibited the biofilm formation at concentrations lower than that needed for cuminaldehyde. Carvacrol showed better anti-biofilm effect against single- and mixed-species biofilms during the first phases (adhesion phase $4 \mathrm{~h}$ and initial colonization $24 \mathrm{~h}$ ) compared to the maturation phase (48 h). 


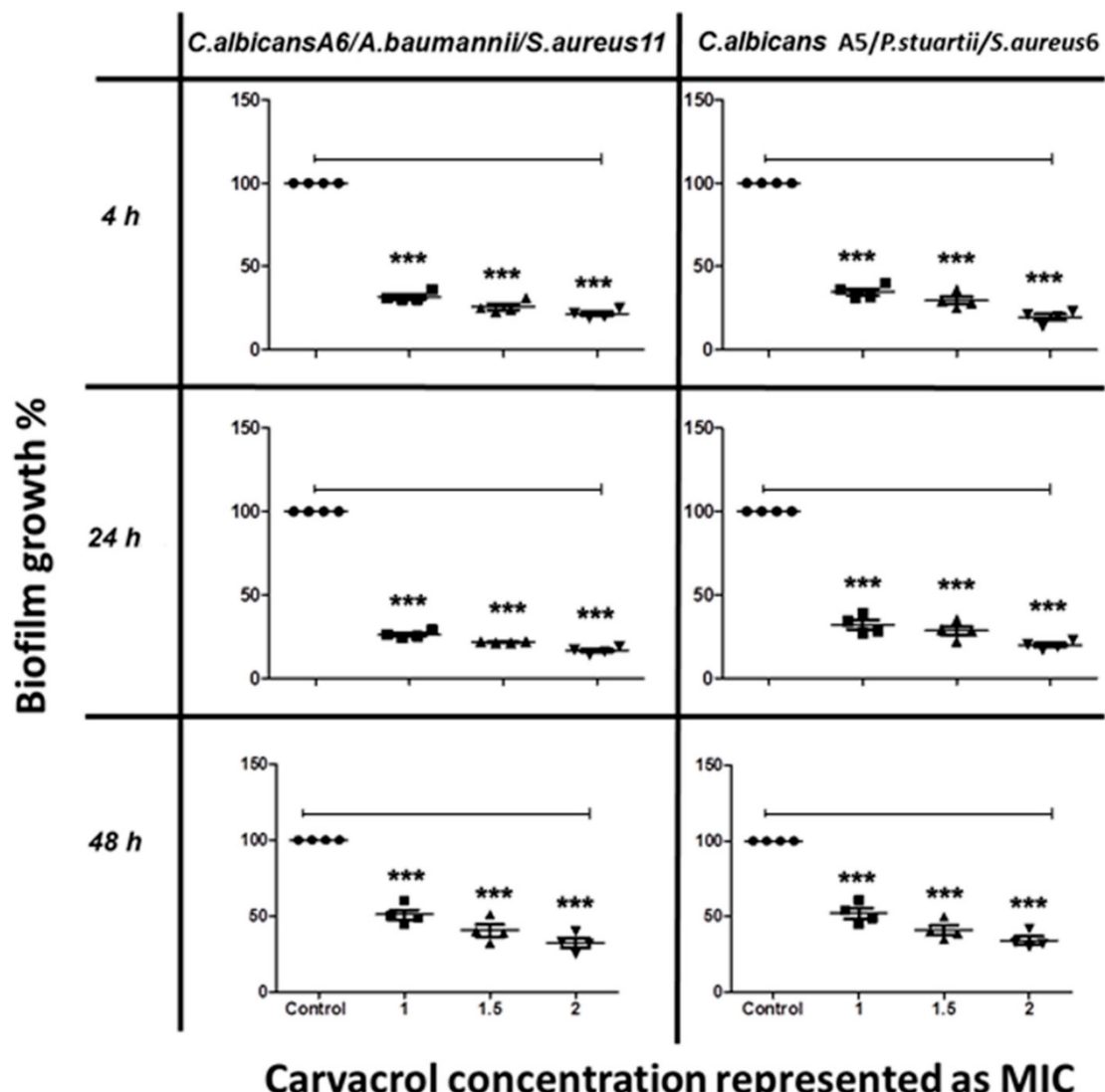

Figure 3. The inhibitory effect of carvacrol on C. albicans/bacteria in mixed biofilm formation at different time points, as determined by MTT viability assays. C. albicans cells were allowed to adhere onto 96 well microtiter plates at time points of $4 \mathrm{~h}, 24 \mathrm{~h}$, and $48 \mathrm{~h}$, followed by treatment with various concentrations of carvacrol at 1.0, 1.5, and 2.0 MIC prior to incubation at $37^{\circ} \mathrm{C}$. The anti-biofilm activity of the compound was assessed by measuring the metabolic activity of viable cells by MTT assay. The data were analyzed using one-way ANOVA and statistical significance was calculated with Dunn's multiple comparison test. Significance level is indicated by asterisks. The data display the mean \pm standard error (SEM) of four replicates.

\subsection{Optimum Inhibition of C. albicans by Combination of Yeast and Plant Terpenoids}

Carvacrol effectively inhibited both Candida forms in lower doses, and had the capability to penetrate the formed biofilms. Thus, a combination of farnesol, a hyphae-specific inhibitor, and carvacrol showed non-selective inhibition effect on C. albicans either in yeast (Table 2) or hyphae/biofilm forms (Figure 5). The combined treatment was effective against hyphae formed by $C$. albicans both incubated alone (Figure 5A,C,D) or when mixed with co-isolated bacteria (Figure 5B,E,F). The interaction was synergistic. 
Table 2. Interactions (indicated by FIC indices) of carvacrol in combination with farnesol against C. albicans after $48 \mathrm{~h}$ of incubation.

\begin{tabular}{|c|c|c|c|c|c|}
\hline \multirow{2}{*}{ Strains } & \multicolumn{3}{|c|}{ MIC (mg/mL) } & \multirow{2}{*}{ FICI $^{*}$} & \multirow{2}{*}{ Interactions } \\
\hline & Carvacrol & Farnesol & Carvacrol/Farnesol & & \\
\hline ATCC10231 & 0.5 & 150 & $0.03+0.2$ & 0.06 & Synergy \\
\hline A1 & 0.5 & 16.8 & $0.125+1.2$ & 0.33 & Synergy \\
\hline A2 & 0.5 & 33.6 & $0.03+1.2$ & 0.10 & Synergy \\
\hline A3 & 1 & 33.6 & $0.06+0.2$ & 0.06 & Synergy \\
\hline A4 & 0.25 & 33.6 & $0.03+0.4$ & 0.13 & Synergy \\
\hline A5 & 1 & 33.6 & $0.125+1.2$ & 0.17 & Synergy \\
\hline A6 & 0.5 & 33.6 & $0.06+1.2$ & 0.16 & Synergy \\
\hline A7 & 0.5 & 33.6 & $0.125+0.4$ & 0.26 & Synergy \\
\hline A8 & 1 & 16.8 & $0.25+0.4$ & 0.28 & Synergy \\
\hline A9 & 1 & 33.6 & $0.25+0.4$ & 0.26 & Synergy \\
\hline A10 & 0.5 & 33.6 & $0.06+0.8$ & 0.15 & Synergy \\
\hline A11 & 1 & 33.6 & $0.25+0.8$ & 0.28 & Synergy \\
\hline A12 & 0.5 & 33.6 & $0.125+1.2$ & 0.29 & Synergy \\
\hline A13 & 1 & 33.6 & $0.25+0.8$ & 0.28 & Synergy \\
\hline A14 & 0.5 & 16.8 & $0.125+1.2$ & 0.33 & Synergy \\
\hline A15 & 1 & 33.6 & $0.125+1.2$ & 0.15 & Synergy \\
\hline
\end{tabular}

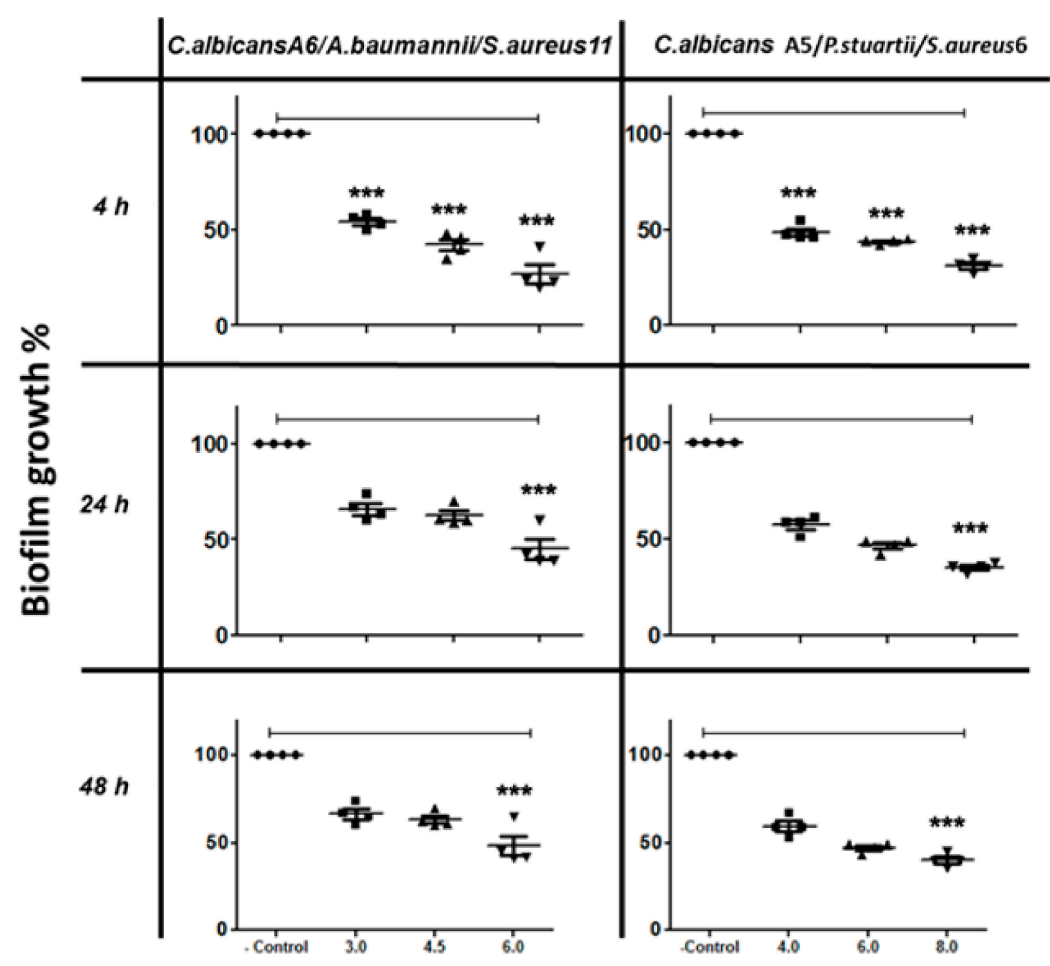

Cuminaldehyde concentration $(\mathrm{mg} / \mathrm{mL})$

Figure 4. The inhibitory effect of cuminaldehyde on C. albicans/bacteria in mixed-species biofilm at different time points, as determined by MTT reduction assays. C. albicans cells were allowed to adhere onto 96 well plates at different times $(4 \mathrm{~h}, 24 \mathrm{~h}$, and $48 \mathrm{~h}$ ), followed by treatment with various cuminaldehyde concentrations prior to incubation at $37^{\circ} \mathrm{C}$. The anti-biofilm activity of the compound was assessed in terms of metabolic activity by MTT assay. The data were analyzed using one-way ANOVA and statistical significance was calculated with Dunn's multiple comparison test. Significance level is indicated by asterisks. The data display the mean \pm standard error (SEM) of four replicates. 

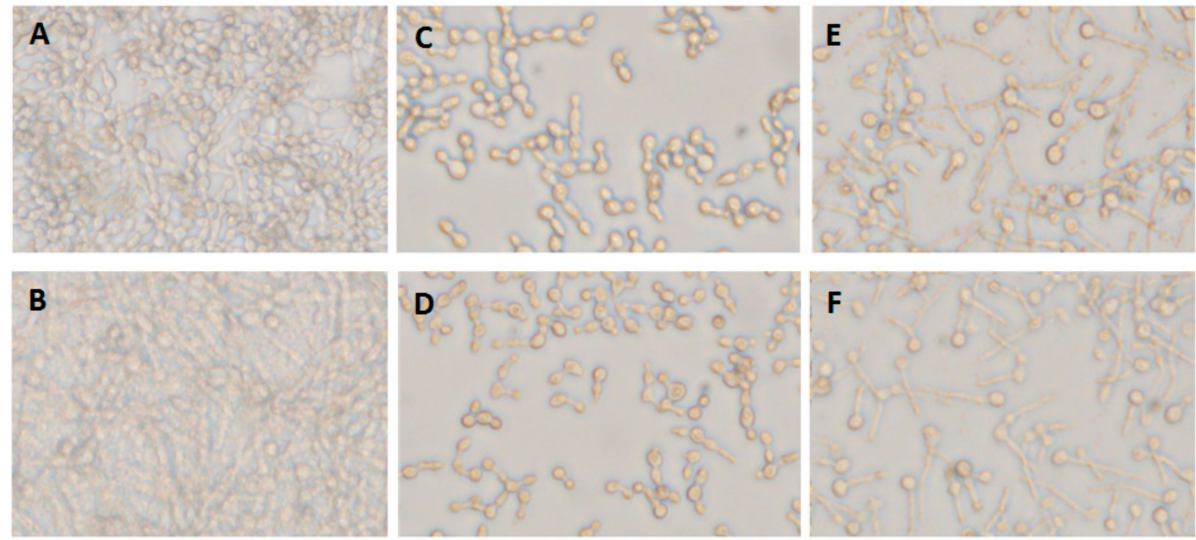

Figure 5. Dual inhibitory effect of farnesol and carvacrol on single- and mixed-species C. albicans biofilm formation. (A) Single-species C. albicans, A5 biofilm formed after $24 \mathrm{~h}$. (B) Mixed-species biofilm formed by C. albicans A5, P. stuartii 3, and S. aureus 6 (A5/Ps3/Sa6). (C) Single-species biofilm treated with farensol at $0.7 \mathrm{mg} / \mathrm{mL}$ in combination with carvacrol at $0.25 \mathrm{mg} / \mathrm{mL}$. (D) Single-species biofilm treated with farensol at $0.7 \mathrm{mg} / \mathrm{mL}$ in combination with carvacrol at $0.5 \mathrm{mg} / \mathrm{mL}$. (E) Mixed-species biofilm treated with farensol at $0.7 \mathrm{mg} / \mathrm{mL}$ in combination with carvacrol at $0.25 \mathrm{mg} / \mathrm{mL}$. (F) Mixed-species biofilm treated with farensol at $0.7 \mathrm{mg} / \mathrm{mL}$ in combination with carvacrol at $0.5 \mathrm{mg} / \mathrm{mL}$.

\section{Discussion}

The MIC values for amphotericin B found in this study were much higher than those reported in various studies for Candida species [29-31] which may be attributable to the capacity of $C$. albicans to develop genetic mutations [32,33], leading to biodiversity [34].

The selective inhibition by farnesol of Candida hyphae formation but not the yeast form was in accordance with several reported data [35-37]. Farnesol treatment may induce Candida apoptosis, disordered mitochondria due to the production of reactive oxygen species [11,38], change in cell development [39], and necrosis [40]. Although farnesol caused inhibition of biofilm formed by single C. albicans species, as previously reported [41,42], it did not reduce the biofilm formed by mixed species. The presence of bacteria is known to increase the resistance of such biofilms [22].

The higher susceptibility of $C$. albicans isolates to carvacrol was in accordance with the Raut et al. 2013 study [15] which reported that carvacrol exerts anti-Candida activity by interfering with endoplasmic reticulum integrity [43] and alteration in calcium homeostasis [44], ergosterol biosynthesis [45], and plasma membrane integrity [46]. Furthermore, our data showed that the combination of carvacrol and cuminaldehyde caused synergistic interactions (FICI values ranged from 0.36 to 0.5 ) to most tested C. albicans strains. The results obtained were in accordance with previous studies confirming the synergistic activity of essential oils, such as lavender oil in combination with Melaleuca alternifolia oil [47] and lavender oil in combination with Pelargonium graveolens oil [48].

Both terpenoids also showed strong inhibition of biofilm formation and penetration capability to formed biofilm. The anti-biofilm activity of terpenoids may be attributed to membrane damage, as well as inhibition of oxidative phosphorylation and respiratory chain functions [49]. Terpenoid-mediated changes in membrane permeability and fluidity can result in the degradation of cell walls, and hence affect the adherence of $C$. albicans to solid surfaces [50]. Furthermore, carvacrol itself at $2 \mathrm{mg} / \mathrm{mL}$ showed $\sim 75 \%$ inhibition of mixed-species biofilm, which was consistent with previous studies of the anti-Candida activity of carvacrol $[43,51,52]$.

Although some studies have shown that mature mixed biofilms of bacteria and Candida exhibit enhanced resistance compared to single-species biofilms [53], the terpenoid compounds used in this study, in particular carvacrol, caused strong inhibition to the biofilm formed by $C$. albicans A6/S. aureus/A. baumannii, despite the cohabitation of multidrug-resistant $A$. baumannii. 
It is important to note that the majority of anti-fungal agents had limited anti-biofilm activity. It was reported that Candida biofilms were 30 to 2000 times more resistant to various antifungal agents compared to their planktonic counterparts [54,55]. The mechanisms by which biofilms develop antimicrobial resistance are complex and multifactorial. These include altered gene expression following surface attachment, reduced growth rates, variable nutrient availability that induces changes in phenotype, and the presence of extracellular polymeric substances that impedes the penetration of antimicrobial agents to biofilm [56].

Some studies have shown that combinations of plant essential oils or their terpenoid components with commercial antimycotics are known to result in synergistic antifungal activities [57,58]. Interestingly, similarly to our synergistic data using carvacrol and farnesol, carvacrol has been reported to have synergistic interactions with fluconazole against the planktonic and biofilm forms of C. albicans [59]. Furthermore, carvacrol has been classified as GRAS (generally recognized as safe) and approved for food use [60], as has cuminaldehyde [61]. The results from this study can be employed both for the prevention of biofilm formation by single or mixed species and for their treatment.

\section{Conclusions}

As concluding remarks, terpenoids showed effective inhibition of different Candida forms, including yeast, hyphae, and biofilm, based on the type of terpenoid used. Endogenous terpenoid (farnesol) produced by C. albicans yeast effectively inhibited Candida hyphae formation, but this was not the case when C. albicans was mixed with bacteria or existed as Candida hyphae/biofilm, indicative of a lack of biofilm-penetration capability. Furthermore, farnesol required $~ 12-50$ times its hyphae inhibitory concentration to inhibit the yeast form. Exogenous plant terpenoids present in our food and condiments showed non-selective inhibition of Candida forms including yeast and hyphae. Combination of exogenous terpenoids with endogenous terpenoids showed a synergistic non-selective inhibition effect on both $C$. albicans forms. Furthermore, the combination showed promising reduction of Candida biofilm, indicative of a penetration capability when compared to available antifungal agents. Importantly, the concentration of the combined terpenoids was significantly reduced $\sim 10-20$ times, a non-toxic concentration available in regular food and condiments, as reported previously. Thus, the terpenoids from this study, in particular carvacrol in combination with farnesol, can be used as protective and therapeutic agents against $C$. albicans in its different forms. Moreover, the combined terpenoids can be used as a promising safe preservative for prosthetic devices.

Supplementary Materials: Tables S1-S6 and Figures S1-S3 are available as Supplementary data at http://www. mdpi.com/2218-273X/10/2/342/s1.

Author Contributions: H.F.Z.T. performed the experiments analyze the data and write the first draft. K.B. and Z.B.-O. help on experiments design and revising the manuscript. G.K. helped on the Candida experiments. M.M. helped on the microscopy work. S.S.M.S. design the experiments; design the manuscript, interpretation of the results, writing the manuscript and final revisions. All authors have read and agreed to the published version of the manuscript.

Funding: This research was funded by University of Tlemcen to HT and University of Sharjah (Grant Number 1601110215-P) to S.S.M.S.

Acknowledgments: We would like to thank the staff of University Hospital (CHU) of Tlemcen and University of Sharjah for their valuable technical assistance. We also would like to extend our thanks to Amira Mahrous and Islam Altayeb from the University of Sharjah for their valuable help and support.

Conflicts of Interest: The authors have declared no conflict of interest.

\section{References}

1. Geffers, C.; Gastmeier, P. Nosocomial infections and multidrug-resistant organisms in Germany: Epidemiological data from kiss (the hospital infection surveillance system). Dtsch. Arztebl. Int. 2011, 108, 87-93. [CrossRef] [PubMed] 
2. Wenzel, R.P.; Gennings, C. Bloodstream Infections Due to Candida Species in the Intensive Care Unit: Identifying Especially High-Risk Patients to Determine Prevention Strategies. Clin. Infect. Dis. 2005, 41, 389-393. [CrossRef] [PubMed]

3. Sydnor, E.R.M.; Perl, T.M. Hospital Epidemiology and Infection Control in Acute-Care Settings. Clin. Microbiol. Rev. 2011, 24, 141-173. [CrossRef] [PubMed]

4. Elewski, B.E. Onychomycosis: Pathogenesis, Diagnosis, and Management. Clin. Microbiol. Rev. 1998, 11, 415-429. [CrossRef]

5. Edwards, J.E.; Lehrer, R.I.; Stiehm, E.R.; Fischer, T.J.; Young, L.S. Severe Candidal Infections. Ann. Intern. Med. 1978, 89, 91-106. [CrossRef]

6. Brand, A. Hyphal Growth in Human Fungal Pathogens and Its Role in Virulence. Int. J. Microbiol. 2011, 2012, 1-11. [CrossRef]

7. Choi, J.Y.; Kwak, Y.G.; Yoo, H.; Lee, S.-O.; Kim, H.B.; Han, S.H.; Choi, H.J.; Kim, H.Y.; Kim, S.R.; Kim, T.H. Trends in the distribution and antimicrobial susceptibility of causative pathogens of device-associated infection in Korean intensive care units from 2006 to 2013: Results from the Korean Nosocomial Infections Surveillance System (KONIS). J. Hosp. Infect. 2016, 92, 363-371. [CrossRef]

8. Cavalheiro, M.; Teixeira, M.C. Candida Biofilms: Threats, Challenges, and Promising Strategies. Front. Med. 2018, 5, 28. [CrossRef]

9. Elving, G.J.; Van Der Mei, H.C.; Van Weissenbruch, R.; Busscher, H.J.; Albers, F.W.J. Comparison of the microbial composition of voice prosthesis biofilms from patients requiring frequent versus infrequent replacement. Ann. Otol. Rhinol. Laryngol. 2002, 111, 200-203. [CrossRef]

10. Peleg, A.Y.; Hogan, D.A.; Mylonakis, E. Medically important bacterial-fungal interactions. Nat. Rev. Genet. 2010, 8, 340-349. [CrossRef]

11. Zhu, J.; Krom, B.P.; Sanglard, D.; Intapa, C.; Dawson, C.C.; Peters, B.M.; Shirtliff, M.E.; Jabra-Rizk, M.A. Farnesol-induced apoptosis in Candida albicans is mediated by Cdr1-p extrusion and depletion of intracellular glutathione. PLoS ONE 2011, 6, e28830. [CrossRef] [PubMed]

12. Alalwan, H.K.A.; Rajendran, R.; Lappin, D.F.; Combet, E.; Shahzad, M.; Robertson, D.; Nile, C.J.; Williams, C.; Ramage, G. The Anti-Adhesive Effect of Curcumin on Candida albicans Biofilms on Denture Materials. Front. Microbiol. 2017, 8, 588. [CrossRef] [PubMed]

13. Alviano, W.; Mendonca-Filho, R.R.; Bizzo, H.R.; Souto-Padrón, T.; Rodrigues, M.L.; Bolognese, A.M.; Souza, M.M.G. Antimicrobial activity of Croton cajucara Benth linalool-rich essential oil on artificial biofilms and planktonic microorganisms. Oral Microbiol. Immunol. 2005, 20, 101-105. [CrossRef] [PubMed]

14. Soliman, S.S.M.; Semreen, M.H.; El-Keblawy, A.A.; Abdullah, A.; Uppuluri, P.; Ibrahim, A.S. Assessment of herbal drugs for promising anti-Candida activity. BMC Complement. Altern. Med. 2017, 17, 257. [CrossRef] [PubMed]

15. Raut, J.S.; Shinde, R.B.; Chauhan, N.M.; Mohan Karuppayil, S. Terpenoids of plant origin inhibit morphogenesis, adhesion, and biofilm formation by Candida albicans. Biofouling 2013, 29, 87-96. [CrossRef] [PubMed]

16. Gilabert, M.; Marcinkevicius, K.; Andujar, S.; Schiavone, M.; Arena, M.E.; Bardón, A. Sesqui- and triterpenoids from the liverwort Lepidozia chordulifera inhibitors of bacterial biofilm and elastase activity of human pathogenic bacteria. Phytomedicine 2015, 22, 77-85. [CrossRef]

17. Amaya, S.; Pereira, J.A.; Borkosky, S.A.; Valdez, J.C.; Bardón, A.; Arena, M.E. Inhibition of quorum sensing in Pseudomonas aeruginosa by sesquiterpene lactones. Phytomedicine 2012, 19, 1173-1177. [CrossRef]

18. Touil, H.F.Z.; Boucherit-Otmani, Z.; Boucherit, K. In vitro activity of antifungal combinations against planktonic and sessile cells of Candida albicans isolated from medical devices in an intensive care department. J. Mycol. Med. 2018, 28, 414-418. [CrossRef]

19. CLSI. Clinical and Laboratory Standards Institute. In M27, Reference Method for Broth Dilution Antifungal Susceptibility Testing of Yeasts, 3rd ed.; Clinical and Laboratory Standards Institute: Wayne, NJ, USA, 2017.

20. CLSI. Clinical and Laboratory Standards Institute. In M07, Methods for Dilution Antimicrobial Susceptibility Tests for Bacteria That Grow Aerobically, 10th ed.; Clinical Laboratory Standards Institute: Wayne, NJ, USA, 2017.

21. Weerasekera, M.M.; Wijesinghe, G.K.; Jayarathna, T.A.; Gunasekara, C.P.; Fernando, N.; Kottegoda, N.; Samaranayake, L.P. Culture media profoundly affect Candida albicans and Candida tropicalis growth, adhesion and biofilm development. Mem. Inst. Oswaldo Cruz. 2016, 111, 697-702. [CrossRef] 
22. Fernandes, R.A.; Monteiro, D.R.; Arias, L.S.; Fernandes, G.L.; Delbem, A.C.B.; Barbosa, D.B. Biofilm formation by Candida albicans and Streptococcus mutans in the presence of farnesol: A quantitative evaluation. Biofouling 2016, 32, 329-338. [CrossRef]

23. Espinel-Ingroff, A.; Fothergill, A.; Peter, J.; Rinaldi, M.; Walsh, T. Testing conditions for determination of minimum fungicidal concentrations of new and established antifungal agents for Aspergillus spp.: NCCLS collaborative study. J. Clin. Microbiol. 2002, 40, 3204-3208. [CrossRef] [PubMed]

24. Johnson, M.; MacDougall, C.; Ostrosky-Zeichner, L.; Perfect, J.R.; Rex, J. Combination Antifungal Therapy. Antimicrob. Agents Chemother. 2004, 48, 693-715. [CrossRef] [PubMed]

25. Ibarra-Trujillo, C.; Villar-Vidal, M.; Gaitán-Cepeda, L.A.; Pozos-Guillen, A.; Mendoza-de Elias, R.; Sánchez-Vargas, L.O. Ensayo de formación y cuantificación de biopelículas mixtas de Candida albicans y Staphylococcus aureus. Revista Iberoam. Micol. 2012, 29, 214-222. [CrossRef] [PubMed]

26. ATCC.org. MTT Cell Proliferation Assay. Available online: http://www.atcc.org/ \{\}/media/ DA5285A1F52C414E864C966FD78C9A79.ashx (accessed on 17 March 2019).

27. Brescia, P.; Banks, P. Quantifying Cytotoxicity of Thiostrepton on Mesothelioma Cells Using MTT Assay and the Epoch $^{\mathrm{TM}}$ Microplate Spectrophotometer; BioTek Instruments, INC.: Winooski, VT, USA, 2009.

28. Meletiadis, J.; Mouton, J.W.; Meis, J.F.; Verweij, P.E. In vitro drug interaction modeling of combinations of azoles with terbinafine against clinical Scedosporium prolificans isolates. Antimicrob. Agents Chemother. 2003, 47, 106-117. [CrossRef]

29. Cordeiro, R.A.; Teixeira, C.E.C.; Brilhante, R.S.N.; Castelo-Branco, D.; Paiva, M.A.N.; Leite, J.J.G.; Lima, D.T.; Monteiro, A.J.; Sidrim, J.J.C.; Rocha, M.F.G. Minimum inhibitory concentrations of amphotericin B, azoles and caspofungin againstCandidaspecies are reduced by farnesol. Med. Mycol. 2013, 51, 53-59. [CrossRef]

30. Shanmughapriya, S.; Sornakumari, H.; Lency, A.; Kavitha, S.; Natarajaseenivasan, K. Synergistic effect of amphotericin B and tyrosol on biofilm formed by Candida krusei and Candida tropicalis from intrauterine device users. Med. Mycol. 2014, 52, 853-861. [CrossRef]

31. Bozó, A.; Domán, M.; Majoros, L.; Kardos, G.; Varga, I.; Kovács, R. The in vitro and in vivo efficacy of fluconazole in combination with farnesol against Candida albicans isolates using a murine vulvovaginitis model. J. Microbiol. 2016, 54, 753-760. [CrossRef]

32. Hirakawa, M.; Martinez, D.A.; Sakthikumar, S.; Anderson, M.Z.; Berlin, A.; Gujja, S.; Zeng, Q.; Zisson, E.; Wang, J.M.; Greenberg, J.M.; et al. Genetic and phenotypic intra-species variation in Candida albicans. Genome Res. 2014, 25, 413-425. [CrossRef]

33. Monteiro, D.; Arias, L.; Fernandes, R.; Da Silva, L.D.; De Castilho, M.; Da Rosa, T.; Vieira, A.; Straioto, F.; Barbosa, D.B.; Delbem, A.C.B. Antifungal activity of tyrosol and farnesol used in combination against Candida species in the planktonic state or forming biofilms. J. Appl. Microbiol. 2017, 123, 392-400. [CrossRef]

34. Hittinger, C.T.; Rokas, A.; Bai, F.-Y.; Boekhout, T.; Gonçalves, P.; Jeffries, T.W.; Kominek, J.; Lachance, M.-A.; Libkind, D.; Rosa, C.A.; et al. Genomics and the making of yeast biodiversity. Curr. Opin. Genet. Dev. 2015, 35, 100-109. [CrossRef]

35. Ramage, G.; Saville, S.P.; Wickes, B.L.; López-Ribot, J.L. Inhibition of Candida albicans Biofilm Formation by Farnesol, a Quorum-Sensing Molecule. Appl. Environ. Microbiol. 2002, 68, 5459-5463. [CrossRef] [PubMed]

36. Nickerson, K.W.; Atkin, A.L.; Hornby, J.M. Quorum Sensing in Dimorphic Fungi: Farnesol and Beyond. Appl. Environ. Microbiol. 2006, 72, 3805-3813. [CrossRef] [PubMed]

37. Polke, M.; Leonhardt, I.; Kurzai, O.; Jacobsen, I. Farnesol signalling inCandida albicans- more than just communication. Crit. Rev. Microbiol. 2017, 44, 230-243. [CrossRef] [PubMed]

38. Langford, M.L.; Atkin, A.; Nickerson, K.W. Cellular interactions of farnesol, a quorum-sensing molecule produced byCandida albicans. Futur. Microbiol. 2009, 4, 1353-1362. [CrossRef]

39. Uppuluri, P.; Mekala, S.; Chaffin, W.L. Farnesol-mediated inhibition ofCandida albicansyeast growth and rescue by a diacylglycerol analogue. Yeast 2007, 24, 681-693. [CrossRef] [PubMed]

40. Dumitru, R.; Navarathna, D.H.M.L.P.; Semighini, C.P.; Elowsky, C.G.; Dumitru, R.V.; Dignard, D.; Whiteway, M.; Atkin, A.L.; Nickerson, K.W. In Vivo and In Vitro Anaerobic Mating in Candida albicans. Eukaryot. Cell 2007, 6, 465-472. [CrossRef]

41. Dižová, S.; Bujdáková, H. Properties and role of the quorum sensing molecule farnesol in relation to the yeast Candida albicans. Pharmazie 2017, 72, 307-312. 
42. Fernandes, R.A.; Monteiro, D.; Arias, L.S.; Fernandes, G.L.; Delbem, A.C.B.; Barbosa, D.B. Virulence Factors in Candida albicans and Streptococcus mutans Biofilms Mediated by Farnesol. Indian J. Microbiol. 2018, 58, 138-145. [CrossRef]

43. Chaillot, J.; Tebbji, F.; Remmal, A.; Boone, C.; Brown, G.W.; Bellaoui, M.; Sellam, A. The Monoterpene Carvacrol Generates Endoplasmic Reticulum Stress in the Pathogenic Fungus Candida albicans. Antimicrob. Agents Chemother. 2015, 59, 4584-4592. [CrossRef]

44. Rao, A.; Zhang, Y.; Muend, S.; Rao, R. Mechanism of Antifungal Activity of Terpenoid Phenols Resembles Calcium Stress and Inhibition of the TOR Pathway. Antimicrob. Agents Chemother. 2010, 54, 5062-5069. [CrossRef]

45. Ahmad, A.; Khan, A.; Akhtar, F.; Yousuf, S.; Xess, I.; Khan, L.A.; Manzoor, N. Fungicidal activity of thymol and carvacrol by disrupting ergosterol biosynthesis and membrane integrity against Candida. Eur. J. Clin. Microbiol. Infect. Dis. 2010, 30, 41-50. [CrossRef] [PubMed]

46. Chami, N.; Bennis, S.; Chami, F.; Aboussekhra, A.; Remmal, A. Study of anticandidal activity of carvacrol and eugenol in vitro and in vivo. Oral Microbiol. Immunol. 2005, 20, 106-111. [CrossRef] [PubMed]

47. Cassella, J. Synergistic antifungal activity of tea tree (Melaleuca alternifolia) and lavender (Lavandula angustifolia) essential oils against dermatophyte infection. Int. J. Aromather. 2002, 12, 2-15. [CrossRef]

48. De Rapper, S.; Kamatou, G.; Viljoen, A.; Van Vuuren, S. The In Vitro Antimicrobial Activity of Lavandula angustifolia Essential Oil in Combination with Other Aroma-Therapeutic Oils. Evidence Based Complement. Altern. Med. 2013, 2013, 1-10. [CrossRef] [PubMed]

49. Pauli, A. Anticandidal low molecular compounds from higher plants with special reference to compounds from essential oils. Med. Res. Rev. 2006, 26, 223-268. [CrossRef]

50. Marcos-Arias, C.; Eguia, A.; Madariaga-Torres, L.; Quindós, G. In vitro activities of natural products against oral Candida isolates from denture wearers. BMC Complement. Altern. Med. 2011, 11, 119. [CrossRef]

51. Gallucci, M.; Carezzano, M.; Oliva, M.; Demo, M.; Pizzolitto, R.; Zunino, M.; Zygadlo, J.A.; Dambolena, J.S. In vitroactivity of natural phenolic compounds against fluconazole-resistantCandidaspecies: A quantitative structure-activity relationship analysis. J. Appl. Microbiol. 2014, 116, 795-804. [CrossRef]

52. Inouye, S.; Takahashi, M.; Abe, S. Inhibitory activity of hydrosols, herbal teas and related essential oils against filament formation and the growth of Candida albicans. Nippon. Ishinkin Gakkai Zasshi 2009, 50, 243-251. [CrossRef]

53. Adam, B.; Baillie, G.S.; Douglas, L.J. Mixed species biofilms of Candida albicans and Staphylococcus epidermidis. J. Med Microbiol. 2002, 51, 344-349. [CrossRef]

54. Hawser, S.P.; Douglas, L.J. Resistance of Candida albicans biofilms to antifungal agents in vitro. Antimicrob. Agents Chemother. 1995, 39, 2128-2131. [CrossRef]

55. Seddiki, S.; Boucherit-Otmani, Z.; Boucherit, K.; Kunkel, D. Fungal infectivities of implanted catheters due to Candida sp. Biofilms formation and resistance. J. Mycol. Med. 2015, 25, 130-135. [CrossRef] [PubMed]

56. Douglas, L.J. Candida biofilms and their role in infection. Trends Microbiol. 2003, 11, 30-36. [CrossRef]

57. Amber, K.; Aijaz, A.; Immaculata, X.; Luqman, K.; Nikhat, M. Anticandidal effect of Ocimum sanctum essential oil and its synergy with fluconazole and ketoconazole. Phytomedicine 2010, 17, 921-925. [CrossRef] [PubMed]

58. Khan, M.S.A.; Ahmad, I. Antibiofilm activity of certain phytocompounds and their synergy with fluconazole against Candida albicans biofilms. J. Antimicrob. Chemother. 2011, 67, 618-621. [CrossRef]

59. Doke, S.K.; Raut, J.S.; Dhawale, S.; Karuppayil, S.M. Sensitization of Candida albicans biofilms to fluconazole by terpenoids of plant origin. J. Gen. Appl. Microbiol. 2014, 60, 163-168. [CrossRef]

60. Magi, G.; Marini, E.; Facinelli, B. Antimicrobial activity of essential oils and carvacrol, and synergy of carvacrol and erythromycin, against clinical, erythromycin-resistant Group A Streptococci. Front. Microbiol. 2015, 6, 165. [CrossRef]

61. Tsai, K.-D.; Liu, Y.-H.; Chen, T.; Yang, S.-M.; Wong, H.-Y.; Cherng, J.; Chou, K.-S.; Cherng, J.-M. Cuminaldehyde from Cinnamomum verum Induces Cell Death through Targeting Topoisomerase 1 and 2 in Human Colorectal Adenocarcinoma COLO 205 Cells. Nutrients 2016, 8, 318. [CrossRef]

(C) 2020 by the authors. Licensee MDPI, Basel, Switzerland. This article is an open access article distributed under the terms and conditions of the Creative Commons Attribution (CC BY) license (http://creativecommons.org/licenses/by/4.0/). 